\title{
Reliability-Oriented Method of Flexible Pavement Management
}

\author{
Evgenia Uglova ${ }^{1}$, Artem Tiraturyan ${ }^{1, *}$, and Grigory Aslanyan ${ }^{1}$ \\ ${ }^{1}$ Don State Technical University, Department of Highways, 1 Gagarina Square, 344000, Russia
}

\begin{abstract}
The article dwells on the reliability-oriented method of flexible pavement management. The research revealed the limitation of the existing method in the field of highway condition assessment. The proposed approach was applied using the data obtained during the field tests from the operated sections of the M-4 DON Highway. Within the framework of the study the assessment criteria scale for the condition of flexible pavement designs was developed. The integral indicator of the road safety and the pre-failure condition coefficient was calculated with the subsequent designation of repair measures at the sites. Also, the analysis of the results was carried out on the basis of which a pavement strength failure rate curve was plotted. The results of the study were compared with the results obtained in foreign studies on fatigue fracture research.
\end{abstract}

\section{Introduction}

Preservation of the existing highway network is one of the most important economic objectives of any state. Solution of this issue calls for implementation of modern approaches to diagnostics of highway condition and methods of processing of obtained results. Meanwhile it is recognized by the international standards that a reasonable and technically adequate highway management system is the key to their preservation for any length of time. Thus, the target of research in this article is pavement management.

As one of the examples of pavement management mechanisms a method of highway diagnostics and integrated evaluation of their condition by the design speed provision factor (actual safe maximum speed of a passenger car to basic design speed ratio) may be cited. This method was elaborated under the supervision of Prof. A.P. Vasilyev, and it compiled best practices acquired in carrying out activities in traffic and performance assessment of highways [1].

In foreign practice the principal integrated index characterizing the flexible pavement design condition during operation is PCI (pavement condition index) in accordance with ASTM [2]. This index belongs to the group of composite indices of pavement condition [3] and is calculated on the basis of the visual state of the section, i.e. types of defects and their weight coefficients with the scale from 0 to 100 .

\footnotetext{
* Corresponding author: tiraturjan@list.ru
} 
The dependence for annualized PCI variation was suggested by Professor B.S. Radovsky [4,5] proceeding from the assumption of the normal law of distribution of the factors contributing thereto:

$$
P C I(t)=100 \cdot \Phi\left\{\frac{1}{C}\left[1-\left(\frac{t}{T}\right)^{\frac{1}{b}}\right]\right\}
$$

where $\Phi(\mathrm{x})$ stands for the error function;

$\mathrm{t}$ stands for the time period at the lapse of which the PCI is obtained;

$\mathrm{T}$ stands for the time until halving of the initial estimate depending on the pavement design, the environmental conditions of its operation and the traffic volume, which was reduced to the design load.

b stands for the invariable indicative of the material resistance to repeated stress;

c stands for the coefficient of variation indicative of dispersion of the safety factor about its mean.

When analyzing the graphic display of this relation (Figure 1) it should be noted that the degradation curves are subject to the classical normal distribution and depend heavily on the values of the initial parameters [5].

At the same time it should be noted that the parameters included in this relation are rather subjective, since it is not strictly stipulated what is taken to mean the initial estimate (strength, roughness, rutting or any other factors). Similarly the practices in the Russian Federation have no universal concept of pavement design failure for pavements.

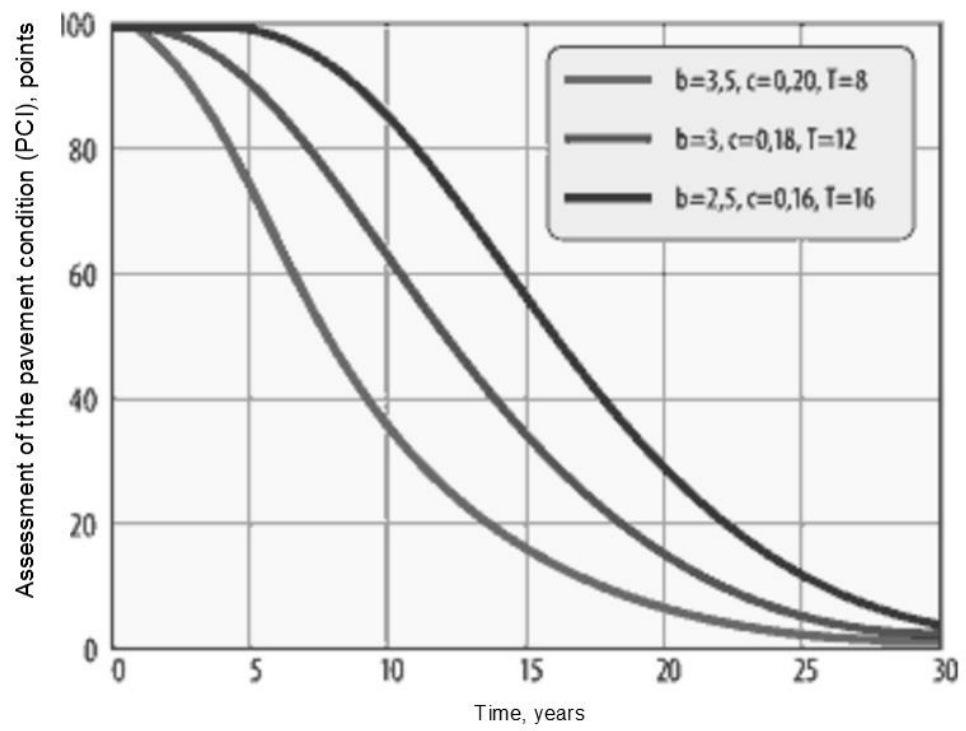

Fig. 1. Degradation curves of the flexible pavement design condition for various parameters of the pavement design condition and the strength parameters dispersion

For example, ODN 218.046 - 01 gives the following definition of the failure condition: "Strength failure of the pavement design can be physically manifested in appearance of longitudinal and transversal roughness of the pavement surface associated with the design strength (transversal roughness, rutting, fatigue cracking) with further evolving of other types of strains and fractures (frequent cracking, crack pattern, potholes, hollow spots, fractures, etc.)." Quantitatively the pavement design failure is characterized by the marginal fracture ratio represented by the relation of the cumulative length (or cumulative area) of 
the highway sections needing repair due to inadequate strength of pavement to the total length (or total area) of the highway between the city pairs.

Thus a contradiction emerges as to which of the fracture type prevails in the event of failure recognition; whether to consider the section, which has recently been repaired, but examination of which has shown non-conformity of the actual total elasticity modulus with the minimum required value, failed, etc. Thus, topicality of the research accounts for the need to shape the new reliability-oriented approach with clearly established criteria related to the technical and operating condition of pavements.

All the above premises together with the necessity of ensuring the required 24 - year times between overhauls of flexible pavements call for creation of a modern reliabilityoriented management system for the flexible pavement design condition. The point of reliability-oriented systems $[6,7,8]$ is that during making of engineering decisions on the facility maintenance no provision exists for the definition of the residual operation life or the time between overhauls. The facility will be operated until the failure rate exceeds the admissible limit values. There is no doubt that implementation of such system should be based on application of modern methods and equipment during pavement diagnostics.

\section{Methods}

The range of the diagnostic equipment applied in the Russian practices has recently been significantly expanded to include modern shock loading devices such as the FWD [9-12], mobile laboratories enabling registration of all the principal performance parameters including longitudinal and transversal roughness, video recording of the pavement condition. The main benefit of these types and kinds of equipment is the estimability of each index along the whole length of the highway. Thus, it is practical to establish the scale of acceptable, satisfactory, pre-failure and poor condition for each index of pavement condition (i.e. strength, roughness, average score, by visual estimation), which will enable to effect a significantly more detailed description of the condition of the surveyed section (Table 1).

Table 1. Assessment criteria for the condition of flexible pavement designs

\begin{tabular}{|l|c|c|c|}
\hline \multicolumn{1}{|c|}{ Condition } & Strength factor & Visual estimate & Roughness \\
\hline $\begin{array}{l}\text { According to } \\
\text { standard }\end{array}$ & $\geq 1.3$ & $4.5-5.0$ & $<2.6$ \\
\hline Satisfactory & $1.21-1.3$ & $4-4.5$ & $2.6-2.9$ \\
\hline Pre-failure & $\underline{1.0-1.21}$ & $\underline{\underline{3.5}-\underline{4.0}}$ & $\underline{2.9}-\underline{3.2}$ \\
\hline Failure & $\underline{\underline{3.0}}$ & $\underline{3.5}$ & $\underline{3.2}$ \\
\hline
\end{tabular}

Thus, during survey of the highway condition the actual values of the pavement length are identified which are characterized by a certain condition.

As principal parameters indicative of the section condition it is suggested to use the safety integrity level Psafety and the pre-failure coefficient Kpre-fail, identified taking into account assessment of strength, longitudinal roughness, visual estimate (Table 2).

Table 2. Matrix of the repair work selection on the basis of the technical and operating condition of the surveyed section

\begin{tabular}{|l|c|c|c|c|c|c|c|}
\hline Parameter & \multicolumn{6}{|c|}{ Parameter meaning } \\
\hline $\begin{array}{l}\text { Residual } \\
\text { operation }\end{array}$ & \multicolumn{3}{|c|}{$\begin{array}{l}\text { \% of the section length corresponding to the values of residual operation life } \\
\text { (pavement strength factor) }\end{array}$} \\
\cline { 2 - 7 } \begin{tabular}{l} 
life $\begin{array}{l}\text { according } \\
\text { to the }\end{array}$ \\
\cline { 2 - 7 }
\end{tabular} & $\begin{array}{c}\text { Failure } \\
\text { pre-failure }\end{array}$ & satisf. & stand. & $\begin{array}{c}\text { failu } \\
\text { re }\end{array}$ & $\begin{array}{c}\text { pre- } \\
\text { failure }\end{array}$ & satisf. & $\begin{array}{c}\text { stand } \\
\text {. }\end{array}$ \\
\hline
\end{tabular}




\begin{tabular}{|c|c|c|c|c|c|c|c|c|}
\hline \multirow{9}{*}{$\begin{array}{l}\text { actual } \\
\text { condition } \\
\text { of the } \\
\text { pavement } \\
\text { design }\end{array}$} & $<1$ & $1-1.21$ & $\begin{array}{l}1.21- \\
1.3\end{array}$ & $>1.3$ & $<1$ & $1-1.21$ & $\begin{array}{c}1.21- \\
1.3 \\
\end{array}$ & $>1.3$ \\
\hline & 6 & 20 & 15 & 47 & 33 & 19 & 4 & 33 \\
\hline & \multicolumn{8}{|c|}{$\%$ of the section corresponding to the average score by visual estimate } \\
\hline & $\begin{array}{l}0- \\
3.5\end{array}$ & $3.5-4.0$ & $4-4.5$ & $\begin{array}{c}4.5- \\
5.0\end{array}$ & $\begin{array}{l}0- \\
3.5\end{array}$ & $3.5-4.0$ & $4-4.5$ & $\begin{array}{c}4.5- \\
5.0\end{array}$ \\
\hline & $\mathbf{0}$ & $\mathbf{0}$ & 20 & 80 & $\mathbf{0}$ & $\mathbf{0}$ & $\mathbf{0}$ & 100 \\
\hline & \multicolumn{8}{|c|}{$\%$ of the section corresponding to the longitudinal roughness IRI value } \\
\hline & \multicolumn{4}{|c|}{ Forward direction } & \multicolumn{4}{|c|}{ Reverse direction } \\
\hline & $>3.2$ & $2.9-3.2$ & $2.6-2.9$ & $\begin{array}{l}0- \\
2.6\end{array}$ & $>3.2$ & $2.9-3.2$ & $2.6-2.9$ & $\begin{array}{l}0- \\
2.6\end{array}$ \\
\hline & 8 & 9 & 6 & 83 & 5 & 5 & 1 & 89 \\
\hline \multicolumn{9}{|c|}{ Specific safety levels of the surveyed section: } \\
\hline \multicolumn{4}{|c|}{ Forward direction } & \multicolumn{5}{|c|}{ Reverse direction } \\
\hline \multicolumn{4}{|c|}{$\begin{array}{l}\text { According to the actual strength factor- } \\
94 \% \\
\text { According to the visual condition-100\% } \\
\text { According to the longitudinal roughness } \\
\text { index-92\% }\end{array}$} & \multicolumn{5}{|c|}{$\begin{array}{l}\text { According to the actual strength factor-67\% } \\
\text { According to the visual condition- } 96 \% \\
\text { According to the longitudinal roughness index- } \\
95 \%\end{array}$} \\
\hline \multicolumn{9}{|c|}{ SAFETY INTEGRAL LEVEL OF THE SECTION } \\
\hline \multicolumn{4}{|c|}{$86 \%$} & \multicolumn{5}{|c|}{$61 \%$} \\
\hline \multicolumn{9}{|c|}{ Pre-failure coefficient } \\
\hline \multicolumn{4}{|c|}{0.60} & \multirow{2}{*}{\multicolumn{5}{|c|}{ nn }} \\
\hline \multicolumn{8}{|c|}{ Recommendation on repair works } & \\
\hline \multicolumn{4}{|c|}{$\begin{array}{c}\text { Installation of a seal coating (carpet } \\
\text { coating) }\end{array}$} & \multicolumn{5}{|c|}{ Execution of pavement repair works } \\
\hline
\end{tabular}

*red stands for failure;

*orange stands for pre-failure;

*yellow stands for satisfactory condition;

* green stands for the condition according to the standard;

Calculation of the safety integral index is done according to the following formula:

$$
P_{\text {safety }}=\left(1-P_{\text {strength }}^{\text {fail }}\right) \cdot\left(1-P_{\text {rough }}^{\text {fail }}\right) \cdot\left(1-P_{\text {vis.est }}^{\text {fail }}\right)
$$

where $\mathrm{P}_{\text {strength }}$ stands for the portion of the length of the section with poor strength (failure);

$\mathrm{P}_{\text {rough }}$ stands for the portion of the length of the surveyed section with poor strength (failure);

$\mathrm{P}_{\text {vis.est. }}$ stands for the portion of the length of the surveyed section with the poor average score by visual estimate (failure).

With the values of the safety integral index lower than 0.5 it is necessary to carry out an overhaul.

If $\mathrm{P}_{\text {safety }}>0.5$ the pre-failure coefficient is calculated.

$$
P_{\text {safety }}=\left(1-P_{\text {strength }}^{\text {pre-fail }}\right) \cdot\left(1-P_{\text {rough }}^{\text {pre-fail }}\right) \cdot\left(1-P_{\text {vis.est }}^{\text {pre-fail }}\right)
$$

$\mathrm{P}_{\text {strength }}$ stands for the portion of the length of the section in pre-failure condition in terms of strength (failure+pre-failure);

$\mathrm{P}_{\text {rough }}$ stands for the portion of the length of the surveyed section in pre-failure condition in terms of roughness (failure+pre-failure);

$\mathrm{P}_{\text {vis.est }}$ stands for the portion of the length of the surveyed section in pre-failure condition by visual estimate (failure+pre-failure). 
With $\mathrm{K}_{\text {pre-fail }}<0.5$ repair of asphalt concrete pavement is advised. With $\mathrm{K}_{\text {pre-fail }}>0.5$ works on installation of seal coatings (carpet coatings) are advised.

\section{Results and Discussion}

Below are the results of testing of this approach on the operated sections of M4 DON Highway (Table 3).

Table 3. Results of assessment of the safety integrity level and pre-failure coefficient on the operated sections of highways

\begin{tabular}{|c|c|c|c|c|c|c|c|}
\hline \multirow[b]{2}{*}{ Section } & \multicolumn{2}{|c|}{ Forward direction } & \multirow{2}{*}{$\begin{array}{l}\text { Type } \\
\text { of } \\
\text { repair }\end{array}$} & \multirow[b]{2}{*}{ Section } & \multicolumn{2}{|c|}{ Reverse direction } & \multirow{2}{*}{$\begin{array}{l}\text { Type } \\
\text { of } \\
\text { repair }\end{array}$} \\
\hline & Psafety & Kpre-fail & & & $\begin{array}{l}\text { Psafet } \\
\text { y }\end{array}$ & $\begin{array}{l}\text { Kpre- } \\
\text { fail }\end{array}$ & \\
\hline $\begin{array}{l}1442+000- \\
1452+000\end{array}$ & 0.94 & 0.93 & $\mathrm{SC}$ & $\begin{array}{l}1442+000- \\
1452+000\end{array}$ & 0.97 & 0.95 & $\mathrm{SC}$ \\
\hline $\begin{array}{l}1205+000- \\
1240+000\end{array}$ & 0.89 & 0.87 & $\mathrm{SC}$ & $\begin{array}{l}877+000- \\
892+000\end{array}$ & 0.88 & 0.84 & $\mathrm{SC}$ \\
\hline $\begin{array}{l}1373+300- \\
1383+000\end{array}$ & 0.89 & 0.87 & $\mathrm{SC}$ & $\begin{array}{l}492+000- \\
517+000\end{array}$ & 0.87 & 0.97 & $\mathrm{SC}$ \\
\hline $\begin{array}{l}892+000- \\
907-000\end{array}$ & 0.86 & 0.81 & $\mathrm{SC}$ & $\begin{array}{l}892+000- \\
907-000\end{array}$ & 0.86 & 0.61 & $\mathrm{SC}$ \\
\hline $\begin{array}{l}492+000- \\
517+000\end{array}$ & 0.84 & 0.92 & $\mathrm{SC}$ & $\begin{array}{l}1205+000- \\
1240+000\end{array}$ & 0.85 & 0.87 & $\mathrm{SC}$ \\
\hline $\begin{array}{l}877+000- \\
892+000\end{array}$ & 0.83 & 0.67 & $\mathrm{SC}$ & $\begin{array}{l}1373+300- \\
1383+000\end{array}$ & 0.82 & 0.71 & $\mathrm{SC}$ \\
\hline $\begin{array}{l}173+800- \\
185+600\end{array}$ & 0.098 & 0.045 & $\mathrm{OH}$ & $\begin{array}{l}132+300- \\
144+000\end{array}$ & 0.1 & 0.05 & $\mathrm{OH}$ \\
\hline
\end{tabular}

SC stands for installation of seal coatings, $\mathrm{OH}$ stands for overhaul, R stands for repair.

It is seen from the above table that to ensure safety of pavement on the majority of the surveyed sections it is sufficient to confine to the works on pavement repair and seal coating (carpet coating) installation, which will ensure significant reduction of dynamic effects exercised on the pavement with the traffic load action and, accordingly, extension of its life.

Thus, the suggested approach enables management of the condition of flexible pavements taking into account the fundamental principles of the RCM method recognized universally and widespread in the field of asset management of a number of entities in the Russian Federation [13 - 16].

In accordance with this method all the basic management processes are described by the curve set forth in Figure 2. 


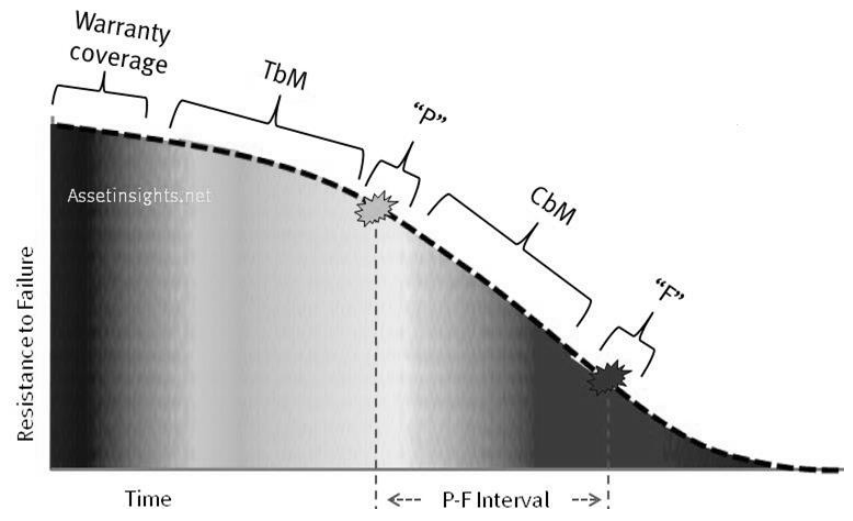

Fig. 2. Pavement condition management chart

Thus, at the first stage upon completion of the construction works and commissioning of the pavement there comes the period of the warranty liabilities secured by the contractor. It is followed by the period of TbM - Time base management that governs fulfillment of scheduled works on pavement maintenance. When the pre-failure point $\mathrm{P}$ (potential failure) is reached, $\mathrm{CbM}$ - condition based management is carried out based on the actual safety level identified following the results of assessment of the actual longitudinal roughness, strength and visual condition. Reasonable planning and selection of preservation measures enable to shift the failure point characterized by the safety integral level $\mathrm{P}_{\text {safety }}<0.5$.

Another important research aspect is determination of the predicted patterns for pavement design failure rates within its operational lifetime. The failure rate is calculated as follows:

$$
\lambda(t)=\frac{f(t)}{P(t)}
$$

where $\lambda(\mathrm{t})$ stands for the pavement length or the number of the sections failed by the instant of time $\mathrm{t}$;

$\mathrm{P}(\mathrm{t})$ stands for the pavement length which did not fail by the instant of time $t$

The data analysis was carried out for the selection of the sections of the M4 DON Highway including the sections with service life from 1 to 16 years. To calculate the failure rate all the highway sections were ranged by the service life, and for each of them the relation between the length of the sections in the strength failure condition and the length of the pavement in satisfactory condition was calculated. On the basis of the obtained calculations the failure rate curve was plotted (Figure 3) corresponding to the curve shape typical in the foreign practices named "bathtub curve" [17-19]. 


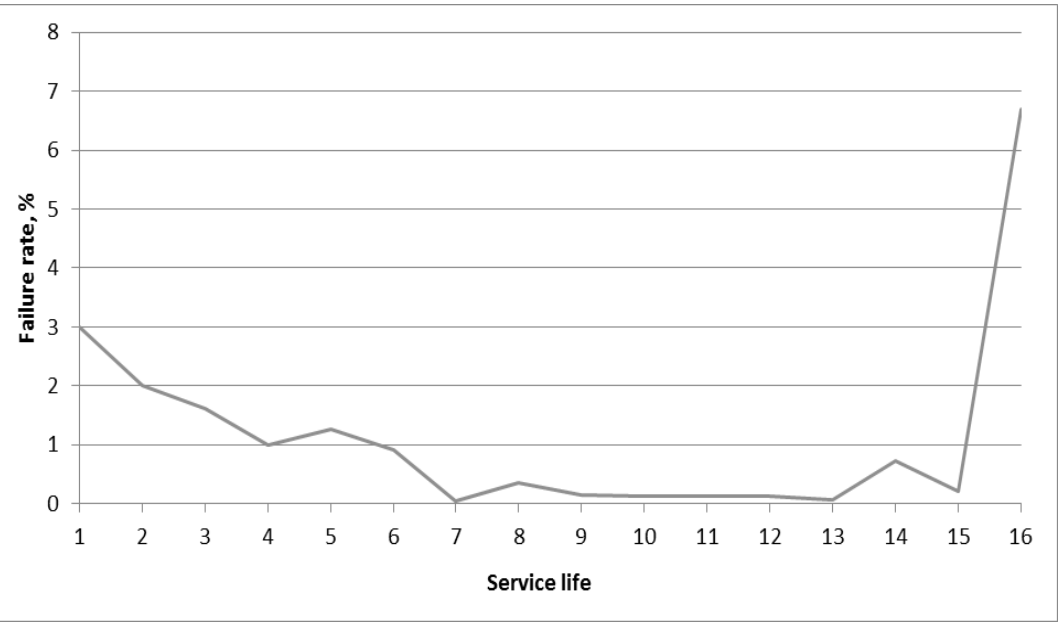

Fig. 3. Pavement strength failure rate curve established according to the field tests

As it is seen from the above graph, in accordance with the classical concepts of the reliability theory three main zones may be identified in the pavement design operation: 1 early failure period ( $0-7$ years), 2 - useful life period ( $7-15$ years), 3 - wear-out period ( $>15$ years). The failure rate curve obtained in this study was compared with the results of the works by Von Quintus [19 - 20] who surveyed the fatigue failure rate accumulation along the length of the operated pavements. As it is seen from the graphs the obtained results are rather close (Figure 4).

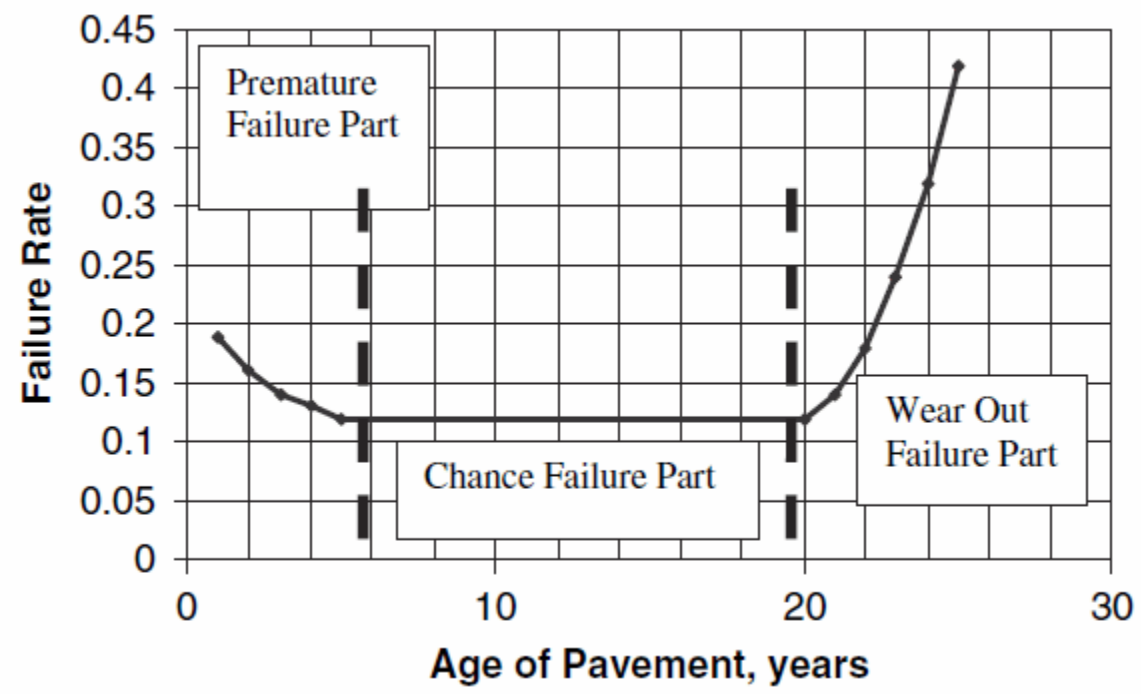

Fig. 4. Pavement strength failure rate curve according to the results of the works by Von Quintus

\section{Conclusions}

1 It is suggested that the condition of the highway section be characterized by the safety integral level calculated based on the length of the pavement in poor condition in terms of 
strength, roughness and visual estimate values identified during field tests with the use of mobile laboratories.

2 The term "pre-failure" was proposed in the context of description of the pavement condition to identify the necessity of works on asphalt concrete pavement repair or works on seal coatings installation.

3 The approach to determination of the measures ensuring preservation of flexible pavements on the network level was developed involving evaluation of the safety integrity level and the pre-failure coefficient:

With the values of the safety integral level lower than 0.5 an overhaul is necessary.

If Psafety $>0.5$, the pre-failure coefficient is calculated

With Kpre-fail $<0.5$ repair of asphalt concrete pavement is advised. With Kpre-fail $>0.5$ works on installation of seal coatings (carpet coatings) are advised

4 On the basis of the statistical data of the flexible pavement condition assessment the shape of the faired curve of the strength failure accumulation rate for flexible pavement was determined for the first time by experiment. The early failure period, useful life period and wear out period were identified. The obtained results conform to the results of the foreign studies dedicated to fatigue failure accumulation.

\section{References}

1. A.P. Vasil'ev, Avtomobil'nye dorogi, 6, 45 (2014)

2. ASTM D6433 - 18. 42 (2018)

3. R. Haas, R. Hudson, Pavement asset management, 428 (2015)

4. B. S. Radovskiy, Izbr. Trudy, 26 (2003)

5. B.S. Radovskiy, Dorozhnaya tekhnika i tekhnologiya, 108 (2006)

6. J.M. Aughenbaugh, J.W. Herrmann, ASME International Design Engineering Technical Conferences (2007)

7. J. Moubray, Reliability-centered maintenance, 2, 440 (2015)

8. Z. Tao, International Conference on Control and Automation, 116 (2017)

9. A.N. Tiraturyan, E.V. Uglova, A.A Lyapin, PNRPU Mechanics Bulletin, 2, 111 (2016)

10. A.N. Tiraturyan, E.V. Uglova, A.A Lyapin. PNRPU Mechanics Bulletin, 2, 178 (2017)

11. A.N. Tiraturyan, E.V. Uglova, Nauka i tekhnika v dorozhnoy otrasli, 3(77), 33 (2016)

12. A.N. Tiraturyan, E.V. Uglova, Procedia Engineering, 742 (2017)

13. V.A. Gapanovich, Tematicheskaya podborka Ispolzovaniye metodologii URRAN, 2 (2014)

14. G. Randall, W. Michael, Engineering Management Journal, 12/4, 25 (2000)

15. J. T. Selvik, T. Aven, Reliability Engineering and System Safety, 2, 324 (2011)

16. V. N. Efimenko, R.V. Moiseenko, MATEC Web of Conferences, 1, 143 (2018)

17. K. Kapur, M. Pecht, Reliability Engineering, 492 (2014)

18. H. Quintus, International Conference on Perpetual Pavements Application of Endurance Limit in M-E Pavement Design, 19 (2006)

19. H. Quintus. NCHRP report 646, 148 (2010) 